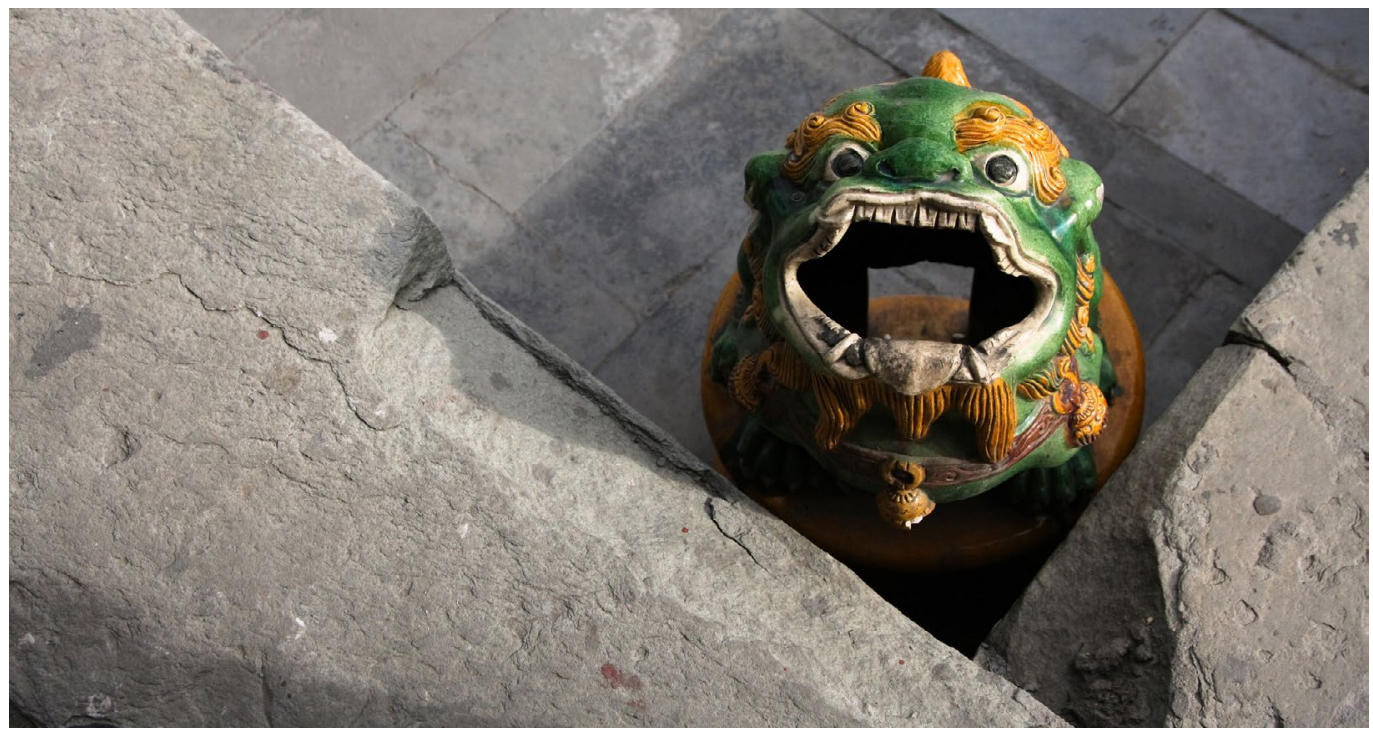

\title{
Garbage as Value and Sorting as Labour in China's New Waste Policy
}

\section{Adam LIEBMAN \\ Goeun LEE}

In 2019, China began implementing a controversial new garbage sorting system in Shanghai. By considering often-unrecognised forms of labour and the interstices of value that many waste objects occupy, this essay examines how waste work has become a site of heightened contestation with multiple types of value in play.

PC: Peiyu Liu, Flickr.com.

cynical. The question 'what kind of garbage are you?' (你是什么垃圾?) - a shortened version of the question asked by sanitation staff when items are being dropped off at garbage stations-came to signify the inconvenience and confusion felt by many urban residents. The remark, which also implies that you are garbage, goes further to capture feelings of 
indictment of those who are used to paying little attention to garbage as they let waste workers deal with it. The controversy over the new rules is therefore not only about the state's gaze extending into a new frontier of people's private lives through an emergent 'eco-dictatorship', a term with Cold-War resonances emphasised in a recent analysis in The Guardian (Kuo 2019). Going beyond this narrow interpretation, we suggest that the controversy is also related to the redistribution of labour (Zhang 2019), especially if labour is viewed broadly to include unregulated and domestic forms.

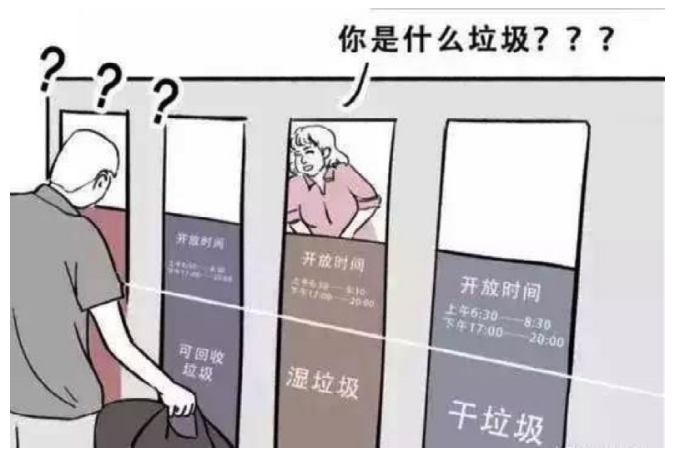

'What kind of garbage are you?' Illustration from a popular WeChat post (WKGY 2019).

Full implementation of the new garbage sorting system, focussed primarily on individual household waste, is set to extend to $46 \mathrm{key}$ cities by the end of 2020 with the help of a state investment of 21.3 billion yuan (3.1 billion USD) (China Daily 2019). How does this attempt to build infrastructure for a government-citizen waste management partnership interact with existing formations of waste labourcomprised of frugal residents, scrap traders, sanitation workers, building cleaners, and more? How is the value imbued in some waste materials redistributed, and whose livelihoods could be negatively impacted? We address these questions by looking at the emergent garbage-sorting project from a perspective that accounts for often-unrecognised forms of labour and the interstices of value that many waste objects occupy. This intervention draws on Adam's long-term ethnographic work in Kunming city, Yunnan province, which was selected in 2007 as one of 26 pilot cities for testing new policies related to managing waste as a 'renewable resource' (Liebman 2018), as well as Goeun Lee's ongoing study of garbage sorting in Shanghai, the pilot city for the most recent policy push.

Our perspective is built on two key points. First, the promotion of 'garbage sorting' (垃 圾分类) is not at all new in China. Important precedents include scrap and kitchen waste collection efforts that were key elements of Mao era political economic planning, promoted for helping the nation develop despite resource shortages. More recently, in response to growing quantities of post-consumer waste (生活垃圾), environmentally-oriented municipal recycling campaigns emerged in China in the early 2000s, although these projects have repeatedly failed (Zhang 2019). Second, the compulsory garbage sorting pilot project in Shanghai should not be understood simply as the Chinese state finally becoming more serious about environmental protection (in a characteristically top-down manner, see for instance Kuo 2019). A complex unfolding of shifts finally set the stage for such strong government action, including but not limited to: falling domestic and global scrap commodity prices in the 2010s (casting more post-consumer waste of marginal value into the category of garbage); municipalities pushing scrap trading industries out of cities while investing in capital-intensive waste incineration plants; and continual increases in the production of disposable products, the mass consumption of those products, and the resulting mass waste. Situating the new waste policy in this broader context suggests that much more is going on than 'a sort of ecodictatorship'. 


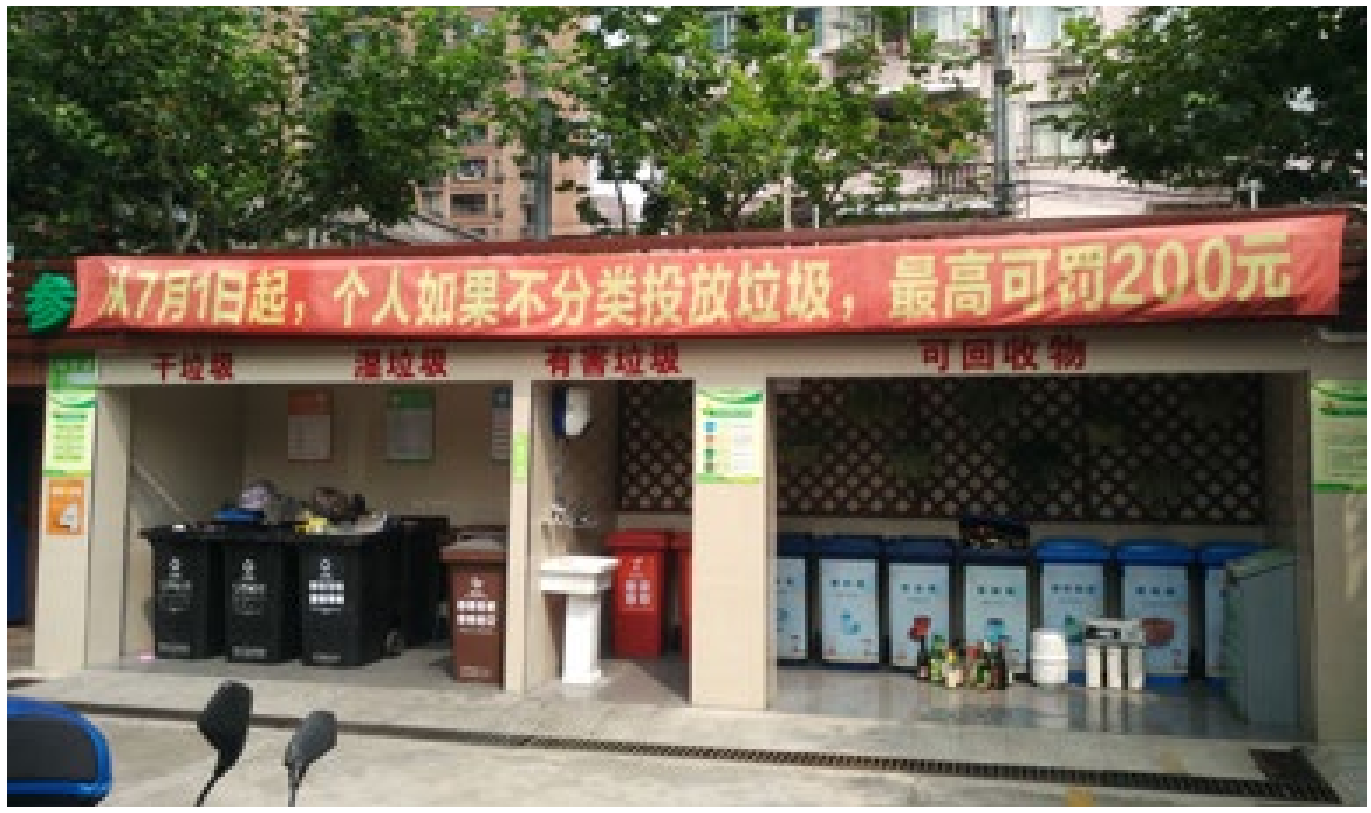

\section{Sorting beyond the Four Categories}

The push to promote garbage sorting in Shanghai has a complex interaction with existing practices of sorting post-consumer waste and urban governance structures. A few weeks after official enforcement began, Goeun followed social organisation representatives who were educating Shanghai neighbourhood residents and sanitation staff about garbage sorting. The Municipal Administration of Afforestation and City Appearance (市容局) was planning to conduct undercover visits to evaluate how well different neighbourhoods were complying with the policy, although lower-level officials and social organisation staff did not know exactly when the visits would occur. Thus, these groups had an interest in regulating neighbourhood practices and discourses in a comprehensive manner to appear earnest about helping implement the new policy in the eyes of the unknown agents. The spectre of surprise visits and evaluations
A newly-renovated Shanghai neighbourhood garbage structure (垃圾箱房) with a banner reading: 'From 1 July, individuals disposing garbage without sorting may be subject to a fine, maximum 200 yuan [28 USD].' PC: Goeun Lee.

has also created competition among the 220 sub-districts of the Shanghai municipality, which started vying for the city's recognition as a 'model' (示范) area.

Care for Nature (pseudonym) is one of the local environmental social organisations that promotes garbage sorting in Shanghai. Xia (pseudonym), a staff member of the organisation, said it would be embarrassing if her sub-district were ranked low. Such embarrassment might also involve a financial cost, since many social organisations receive government funding. Care for Nature claims to specialise in training neighbourhood residents to become more environmentally aware through garbage sorting. Local bureaucrats call the social organisation a 'third party' ( 第三方) since it is not officially part of the government apparatus. Despite not being government officials, social organisations like 
Care for Nature, in addition to neighbourhood volunteers, often perform affective labour through interpersonal communication with residents about following the new sorting rules.

One morning in a Shanghai neighbourhood, shortly after implementation of the new rules, Xia had a tense conversation with a cleaner. She was quite upset to find an opentop, non-standard container for recyclables at the newly renovated garbage structure, and wanted it gone, because the container not only disrupted the nicely-planned four-category system, but also would definitely damage the neighbourhood's 'green evaluation' if seen by monitoring agents. To Xia, it seemed clear that the neighbourhood cleaner was using the container to separate more valuable recyclables, such as plastic bottles, from less valuable items such as glass bottles. She inspected the nonstandard container with glass bottles, which are no longer welcomed by scrap traders due to low prices and difficulties with transportation. The cleaner claimed to know nothing about informal scrap trading, but Xia did not believe it.

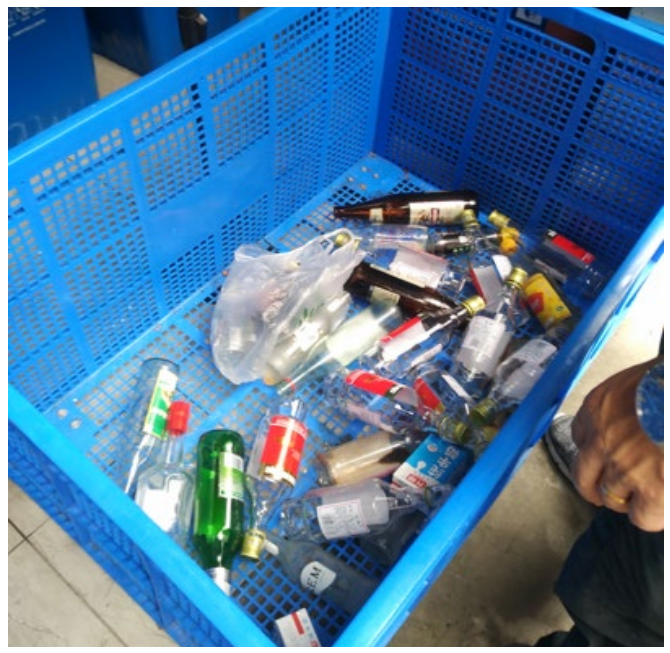

The open-top container that the cleaner refused to remove from the neighbourhood garbage structure. PC: Goeun Lee.
In defence of the open-top container with glass bottles inside it, the neighbourhood cleaner elaborated:

When I'm on-site, the residents separate things well. When I'm not, they don't. The cardboard shipping boxes are so numerous and large, people can't fit the recyclables and the boxes in the limited space provided by the official recyclable containers. So I just let the residents throw in whatever recyclables they have into this wide, open-top container. This neighbourhood isn't my only workplace, I have another neighbourhood where I take care of a garbage structure. When I'm back here, I sort things out in accordance with the new rule.

This rationale seemed to doubly disturb Xia. First, this neighbourhood cleaner made it clear that adequate garbage sorting was often made possible by the hidden manual labour of cleaners. Second, the cleaner was effectively hindering this neighbourhood from being better prepared for undercover monitoring of the new rules, because residents would not learn how to properly sort their garbage if they are instead accustomed to relying on the cleaner-which was the status quo prior to July 2019. Xia implied she understood the real reason that the cleaner would keep the open-top container in the garbage structure: 'I know glass bottles are cheap these days.' With a straight face, the cleaner distanced herself from the subtle allegation by claiming she knew nothing about scrap prices. Eventually, Xia raised her voice: 'If you continue helping the residents like that, it'll be too much work! You're going to be too tired! I just want you to relax and be happy, okay?' Although her words indicated caring, her stern facial expression and sharp tone of voice revealed that she had different concerns.

This story highlights how the standard four categories through which the new garbagesorting project is being implemented might not be in line with the markets still relied on 
for processing much of these materials. The implementation of new garbage-sorting rules in Shanghai is thus a case where old and new practices of handling waste conflict in many ways: not only in defining what is 'recyclable', but also in determining whose practices fit under the umbrella of 'environmental protection', whose labour is recognised and socially valued, who has access to the economic values embodied by some waste objects, and who is stuck with the negative associations that can come from working with waste. As Shanghai is serving as a showcase for the Chinese state's garbage management policy, life there involves negotiation and contestation among people with different interests in defining the value of waste.

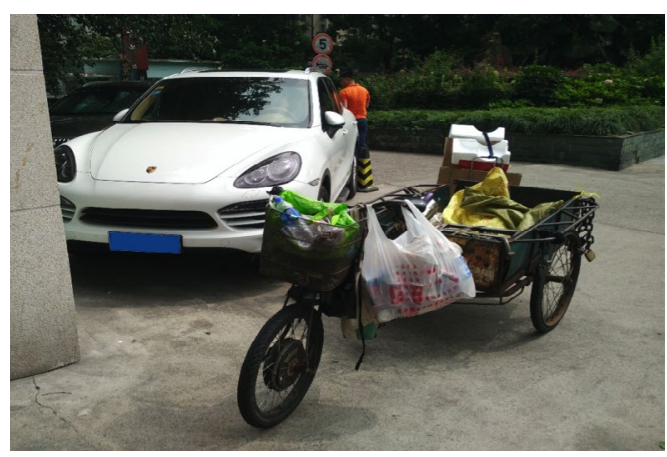

The tricycle of an informal scrap trader, parked at the entrance of an apartment complex in Shanghai. PC: Goeun Lee.

\section{Try Thinking Like a Pig}

Shanghai residents have struggled to decipher the four categories of waste on their own. 'Wet' garbage is meant to be biodegradable materials destined for compost facilities, while 'dry' garbage is meant to be non-hazardous materials that cannot be recycled or composted, destined for incineration plants or landfills. Yet, there also are dry compostables (e.g. peanut shells) and wet garbage sent to landfills (e.g. pig bones) that make the simplified labels confusing. Social media commentary has offered clever guidelines to try to adapt. One popular post on Weibo suggests thinking from the perspective of a pig-arguably the most important animal from a Chinese culinary perspective, and a creature celebrated during the Mao era as a 'fertiliser factory' (化肥厂) and 'treasure bowl' (聚宝盆) that could turn food waste into delicious, protein-rich meat while also producing a crucial soil amendment (Schmalzer 2016, 7 and 12). The pig-inspired guidance instructs: 'If a pig can eat it, it goes into the wet bin. If a pig cannot, it is dry waste. If a pig is likely to die from eating it, the waste is hazardous. If you could sell it and buy a pig with the funds, it is recyclable waste' (see Kuo 2019).

Although clever and culturally resonant, the pig perspective guidelines remain imperfect at best. The final guideline (if it can be sold then it is recyclable) reveals a core contradiction alluded to above. The new regime of four bins is meant to correspond with set material properties and components of waste objects that mark them as wet, dry, hazardous, and recyclable. Yet, whether a post-consumer waste object can be sold is not just determined by its material components. It is also determined by market conditions that are constantly shifting. For example, when commodity values of crude oil drop, the value of scrap plastic drops as it becomes less competitive with new plastics. A drop in the value of scrap plastic cascades through the many links in globalised scrap commodity chains, sometimes causing scrap traders at various links to stop accepting certain types of materials, stop purchasing smaller loads, or even to cease door pickup service. Shifting regulations and politics also have large impacts on the trade (e.g. China's recent bans on waste imports).

The inevitable disconnections between what is considered recyclable from a material-technological standpoint and what a constantly-shifting free market finds profitable to trade as scrap at any one point in time is a key contradiction in environmentally-oriented 
recycling programmes everywhere (MacBride 2012; Reno 2016). Thus, although helpful and well intentioned, the pig-perspective guideline that is based on saleability inadvertently draws attention to the important issue of what happens to waste materials beyond the bin.

The contemporary movement towards implementing garbage sorting in China began as garbage bins with two sides-one for recyclables, one for other waste-first appeared on streets in select cities in the late 1990s. Later, these two-sided bins became standard around the country, but urban residents soon noticed that when garbage trucks came around, the contents of both bins got dumped back together. Such observations made it clear that the state had not invested in the full infrastructure needed to handle and process different kinds of post-consumer waste, and unregulated scrap trades remained the system through which waste materials of value, sorted out from materials of no value, were being processed into raw materials for production.

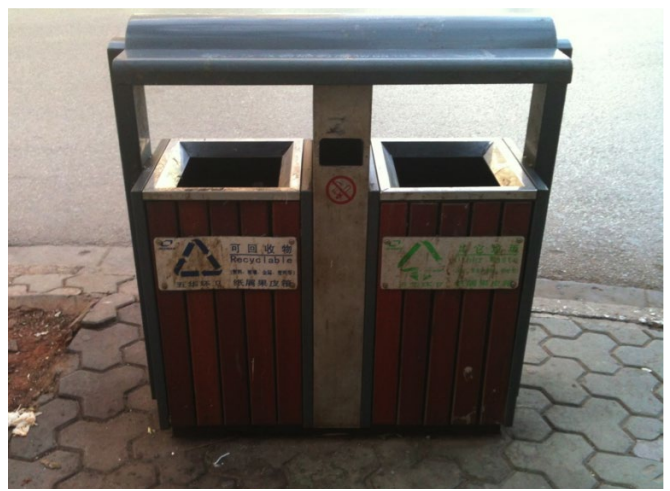

A standard two-sided bin on the streets of Kunming. PC: Adam Liebman.

Some urbanites concerned with recycling for environmental reasons have figured out that the best practice is to leave obviously recyclable waste placed outside of bins, where it is easier for garbage pickers and waste workers to pick up and less likely to be contaminated by other waste. Or, alternatively, they mimic their elders, whose embodied habits of frugality are motivated largely by past hardships, leading them to save sellable waste at home and periodically haul their loads to scrap traders themselves. Yet, due to concerns with the air and water pollution generated by the unregulated processing of scrap and discrimination against the rural migrants who ply scrap trades, younger urbanites do not necessarily consider scrap trading as fitting under the umbrella of 'environmental protection'. These residents instead have been waiting for the infrastructure needed for the coveted citizen-government partnership waste management model. Indeed, many applaud the new garbage sorting policy.

\section{The Revealing Differences between Garbage and Scrap}

In the late 1990s, urban governments mostly withdrew from collecting and processing scrap, an economic sector that had been managed separately from sanitation since the 1950s (Goldstein 2006). Rural migrants filled the void as rapid urbanisation and development created opportunities to eke out a living from waste, and for a lucky few, to strike it rich. Across urban China, successful scrap traders often became a constituent part of the social fabric in the neighbourhoods where they plied their trade and in so doing were guided by factors exceeding economic instrumentality. In fact, a major challenge they have long faced is balancing social obligations with shifting economic realities. With slumping scrap commodity prices in the 2010s, scrap traders' incomes have been negatively affected, straining their relationships in the neighbourhoods where they ply the trade.

In 2014, Adam spoke with a scrap trading couple who rented a relatively cheap storefront in an old neighbourhood in western Kunming. Falling scrap prices, combined with rising rent 


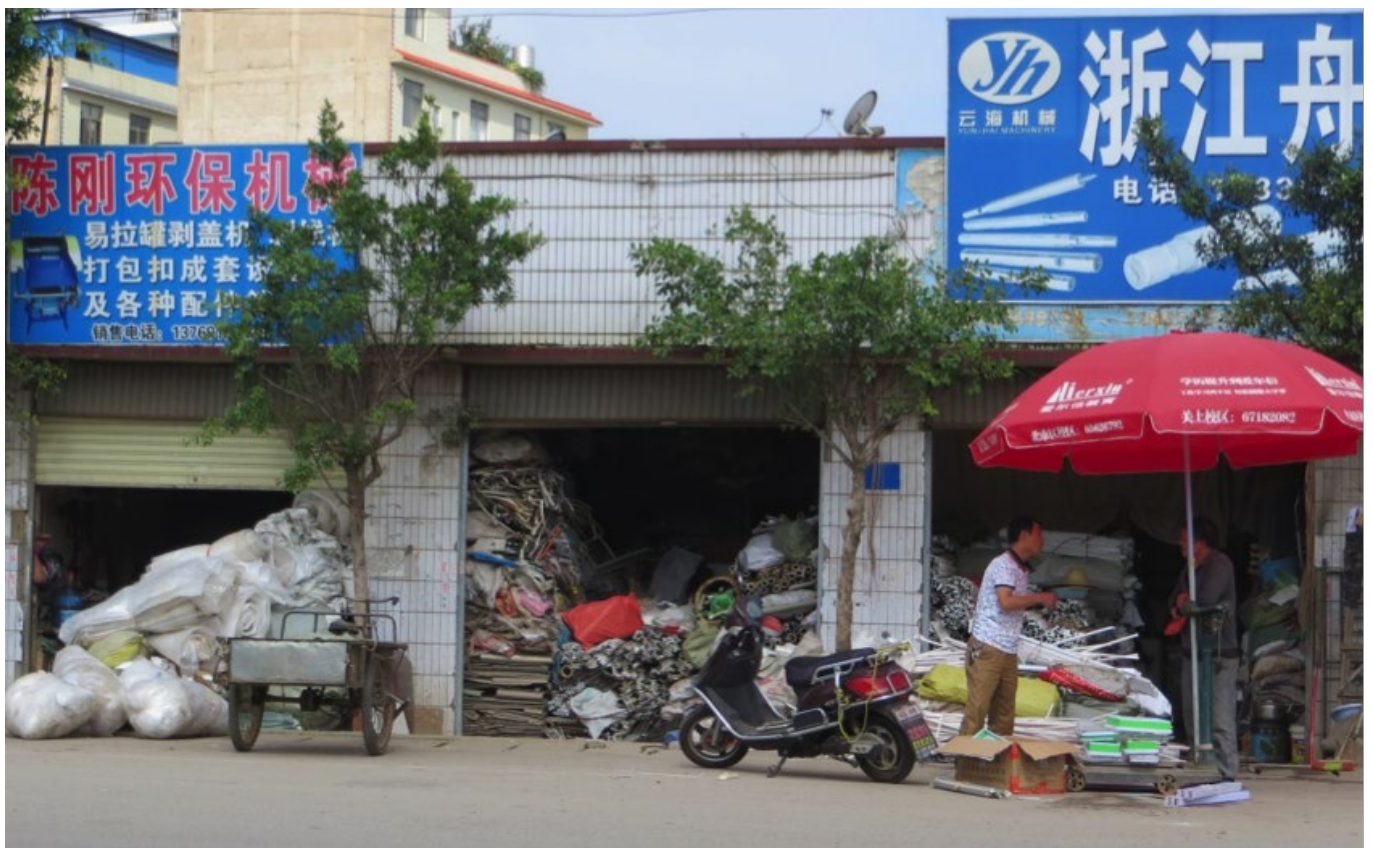

Storefront scrap trading businesses in Kunming. PC: Adam Liebman.

and other costs of living, were making it difficult for this couple to continue earning a modest living. Yet, they had been plying the trade in that neighbourhood for about eight years, and had good relationships with many of the older, low-income residents who lived nearby. They had always been willing to pick up scrap from residents' homes in order to gain more business and maintain relationships, but at the time when Adam conducted the interview, the husband told him that it was no longer worth his time and energy to pick up heavy piles of scrap from homes: 'Yesterday a resident living on the seventh floor across the street had me go move stuff [in a building without an elevator]. I moved over 40 kilograms of old books but in the end made only one "feather" [about 2 US cents] per kilogram. It's so tiring, but it's someone I know, and I would feel bad refusing.'

The husband thus complained that such a paltry economic gain did not outweigh the toll such work took on his aging body, but that reciprocity and human sentiments (人 情) compelled him to agree. Other traders had made the difficult decision, in light of falling prices, to cease offering such services. This upset some urban residents who were not motivated enough to treat their post-consumer waste with the attentive care necessary for maximising potential exchange values, but still enjoyed the convenience, sense of acting morally, and exchange of human sentiments involved with selling more crudely sorted waste to scrap traders. These situations illustrate the importance of frugality and close attention to waste, not just as embodied habits of waste-sorting, but also as forms of labour. Who, if anyone, does the labour of carefully and painstakingly collecting, sorting, and transporting scrap so that it does not simply become garbage has been a major question for many years. 
Most scrap (as waste bearing value) is thus not generated ready-made as such. There is much attention, care, and labour needed to activate the potential exchange values in postconsumer waste. During another conversation, when I asked a scrap trader if she ever feels disrespected by other city residents, she replied that most people are quite good, but, 'earlier this morning a man came with a bag of stuff to sell, and after looking inside I said to him that these things are a total mess, just like garbage, to which he replied: "aren't you a garbage buyer" [with emphasis on the word "garbage"], showing that he looks down on us.'

The way in which the word garbage indicates disrespect in this context is worth a pause. Although both the terms 'garbage' (垃圾) and 'scrap' (废品) have mostly negative connotations in Chinese, the term 'garbage' is more disparaging. No scrap traders advertise that they buy garbage. They typically only use the term when emphasising how some people look down on them: 'Some people think we are collecting garbage.' Indeed, many scrap traders see themselves as crafty middle buyers who add value to the goods they buy through further breaking them down; sorting, packaging, and loading them up, and finally transporting them to larger scale scrap trading businesses or directly to factories.

This subtle difference in terms remains significant in two primary ways. First, the state's efforts to promote garbage sorting conceals how many kinds of post-consumer waste can be imbued with scrap values and are often part of a broader value horizon that involves exchanging human sentiments and balancing relationships. Instead, 'garbage' suggests not only lack of value but also negative value, with the state therefore gaining the honour available as the entity that neutralises this environmental bad, accomplished in part by reallocating sorting labour to citizenconsumers.

At stake in the new garbage-sorting paradigm being piloted in Shanghai, and in similar projects that have come before it, is thus not only a redistribution of the money made through scrap trades and other waste service providers. The new paradigm also involves redistributions of labour and a type of social capital that has been made available through the associations between garbage sorting and protecting the environment. Waste work, to the extent that its form remains contingent on shifts in urban governance structures and market conditions, has become a site of heightened contestation with multiple types of value in play. 
This text is taken from Made in China Journal: Volume 5, Issue 1, 2020, edited by Ivan Franceschini, Nicholas Loubere and Christian Sorace, published 2020 by ANU Press, The Australian National University, Canberra, Australia. 